\title{
Bazedoxifene for the prevention of postmenopausal osteoporosis
}

\author{
Luigi Gennari \\ Daniela Merlotti \\ Vincenzo De Paola \\ Giuseppe Martini \\ Ranuccio Nuti \\ Department of Internal Medicine, \\ Endocrine-Metabolic Sciences \\ and Biochemistry, University of Siena, \\ Policlinico Le Scotte 53 I00-Siena, Italy
}

Correspondence: Luigi Gennari Department of Internal Medicine, Endocrine-Metabolic Sciences and Biochemistry,

University of Siena,

Viale Bracci I, 53100 Siena, Italy

Tel +39577585364

Fax +39577 233446; +39 577233480

Email gennari@unisi.it

\begin{abstract}
Bazedoxifene acetate is a novel, chemically distinct selective estrogen receptor modulator (SERM) that has been specifically developed after a stringent preclinical screening in order to obtain favorable effects on the skeleton and lipid metabolism with the additional improvement of a neutral effect on hot flushes and without stimulating the uterus or the breast. In both preclinical and clinical studies this SERM was shown to maintain BMD, prevent fractures, and reduce total cholesterol. Moreover, bazedoxifene also showed an improved uterine profile and demonstrated estrogen antagonistic activity on the endometrium. Importantly, this latter capacity has led to the development of a novel class of menopausal therapy called tissue selective estrogen complex (TSEC), in which bazedoxifene is combined with conjugated estrogen. The rationale for selecting bazedoxifene as the SERM in this TSEC combination is that it may offset estrogen stimulation of endometrial and breast tissue, without the necessity of using a progestin in women with an intact uterus, without aggravating menopausal vasomotor symptoms, but with an additive effect on bone. Preliminary data from phase 3 clinical trials appear to confirm this hypothesis, showing a greater effect of bazedoxifene on BMD with respect to raloxifene, coupled with efficacy on menopausal vasomotor symptoms not achieved by SERM alone. These properties and the safety profile of this combination, if confirmed long-term in ongoing phase 3 trials, might significantly affect the way women and physicians approach menopause and its related disorders.
\end{abstract}

Keywords: bazedoxifene, SERM, estrogen, postmenopausal osteoporosis, treatment

\section{Introduction \\ Osteoporosis}

Osteoporosis is a skeletal disorder characterized by compromised bone strength and increased risk of fracture (Osteoporosis Prevention, Diagnosis, and Therapy Consensus Statement 2000). It is one of the most common disorders in elderly subjects and represents a major public health problem, affecting up to $40 \%$ postmenopausal women and $15 \%$ of men. Its clinical significance lies in the occurrence of fractures, involving most commonly the forearm, the vertebral bodies and the hip, but fractures at other sites may be also associated with the disease. It has been estimated that in the US, at least $90 \%$ of all hip and spine fractures among elderly white women and more than $70 \%$ of those among elderly white men may be attributed to osteoporosis (Melton et al 1997). The occurrence of osteoporotic fractures leads to considerable mortality, morbidity, reduced mobility and decreased quality of life. Fractures of the hip incur the largest direct cost for health services, giving rise to substantial morbidity and mortality (Center et al 1999). Osteoporotic fractures of the vertebrae are of less economic significance, but also give rise to significant morbidity, causing back pain, disability, kyphosis and height loss (Barrett-Connor 1995). Moreover, future risk of osteoporotic fractures is greatly increased in patients with one or more vertebral fractures and quality of life becomes progressively impaired as the number and 
severity of vertebral fractures increases (Melton et al 1999). In 1999, the annual number of hip fractures in 15 countries of EC has been estimated to be 500,000, with a total care cost of about $€ 4.8$ billion per year (International Osteoporosis Foundation 1999). In US alone, in 2005 there were over 2 million osteoporosis-related fractures, with direct healthcare costs of nearly US\$17 billion (Burge et al 2007). This burden is increasing annually in absolute terms because of the ageing of the population (Cooper et al 1992). Given the magnitude of the problem, the prevention and treatment of osteoporosis is, therefore, of major importance for health organizations in all countries. The major determinant of bone strength and osteoporotic fracture risk is bone mineral density (BMD), as assessed by dual photon absorptiometry (DPA) or dual energy x-ray absorptiometry (DXA). According to WHO criteria, osteoporosis is defined to exist when BMD values fall more than 2.5 standard deviations below the young adult reference mean (Osteoporosis Prevention, Diagnosis, and Therapy Consensus Statement 2000). Many studies indicated that the risk of fragility fractures increases progressively as BMD declines (Cummings et al 1990; Cummings et al 1993; Black et al 1992; Hui et al 1995). However, bone strength depends not only on BMD. Bone size as well as bone quality are other important components that interact with BMD in determining the risk of fracture.

\section{Estrogen deficiency and physiopathology of osteoporosis}

In women, osteoporosis and fractures mainly occur as a consequence of estrogen deficiency after menopause and result from an imbalance between bone resorption by osteoclasts and bone formation by osteoblasts, leading to a net bone loss with each remodeling cycle. A decrease in estrogen production from androgen precursors has also been supposed to be a major cause of bone loss and osteoporosis in aging men (Riggs et al 1998; Khosla et al 2002; Gennari et al 2004). To date, the mechanism by which estrogen affects bone metabolism is complex and not fully elucidated. Possible mechanisms include a decrease in osteoclastogenesis, osteoclast apoptosis and additional effects on calcium homeostasis (Riggs et al 1998; Riggs et al 2002). Estrogen acts through the binding and activation to estrogen receptor $\alpha(\mathrm{ER} \alpha)$ and $\beta(\mathrm{ER} \beta)$. While both the ERs bind estrogen as well as other agonists or antagonists (even though with different affinities), they have distinctly different localizations and concentrations in several tissues, including bone (Gustafsson 1999; Bord et al 2001). In fact, concentrations of ER $\beta$ are higher in developing cancellous bone, whereas concentrations of $\mathrm{ER} \alpha$ are higher in developing cortical bone (Bord et al 2001). Moreover, target cells for estrogen action may contain varying concentrations of homodimers of one or both ERs, as well as ER $\alpha$ and ER $\beta$ heterodimers. Structural functional differences also exist between $\operatorname{ER} \alpha$ and $\operatorname{ER} \beta$, when complexed with estrogen, allowing for a wide range of diverse actions to take place. Importantly, the decrease in estrogen production during menopause has been associated with other nonskeletal complications in women involving lipid metabolism, and the cardiovascular and nervous systems. A decrease in estrogen level has been also associated with menopausal vasomotor symptoms, such as hot flushes, insomnia, nausea and vaginal discharge or bleeding.

\section{Treatment options for osteoporosis}

Among the several therapeutic interventions in osteoporosis, hormone replacement therapy (HRT) has traditionally been seen as the gold standard method of preventing fractures in postmenopausal women, as well as for the management of menopausal symptoms. However, despite both in vivo and in vitro biologically plausible mechanisms for cardiac protection by estrogen and observational studies indicating that HRT confers cardiovascular protection, the Women's Health Initiative (WHI) and other recent randomized, controlled trials have failed to confirm any potential benefit in reducing the risk of coronary artery disease and stroke (Manson et al 2003). Indeed, early increases in cardiac event and stroke rate have been seen in women taking combination HRT. Moreover, HRT, especially if long term, leads to an increased risk of breast cancer and, when unopposed by progestins, endometrial cancer (Vassilopoulou-Sellin 2003). Other side effects often associated with HRT are fluid retention, breast pain, headache and resumption of menstrual cycle. Thus, in many countries the use of HRT is actually limited to a short-term (5 years or less) treatment of menopausal symptom. In contrast, estrogen therapy must be long-term, possibly lifelong, to have any lasting impact on bone health. Alternative therapies for the prevention and the treatment of osteoporosis include bisphosphonates, calcitonin, vitamin D and its active metabolites, selective estrogen receptor modulators (SERMs), strontium ranelate and parathyroid hormone.

\section{SERMS for prevention and treatment of osteoporosis}

SERMs are a class of compounds that can act as ER agonists in some tissues while acting as ER antagonists in others (Cho and Nuttall 2001). They include chemically diverse 
molecules that lack the steroid structure of estrogens, but possess a tertiary structure that allows them to bind to ER $\alpha$ and/or ER $\beta$. Most of the unique pharmacology of SERMs as well as their agonistic and antagonistic activity on estrogen target tissues can be explained by 3 main interactive mechanisms (Riggs and Hartmann 2003): differential ER $\alpha$ and ER $\beta$ expression, differential ER conformation on ligand binding, and differential expression and binding to the ER of coregulator proteins (coactivators or corepressors). Because of their selective estrogen-agonist properties on different target tissues SERMs can be indicated for the prevention or treatment of diseases caused by estrogen deficiency, including osteoporosis, without most of the undesiderable effects of estrogens. In addition, due to their selective estrogen-antagonist properties in the breast, SERMs can be also used to prevent or treat breast cancer, in which estrogen-agonistic activity is undesiderable.

Currently there are two main chemical classes of SERMs approved for clinical use: the triphenylethylene derivatives tamoxifen and toremifene that are used to treat breast cancer, and raloxifene, a benzothiopene derivative indicated for the treatment and prevention of osteoporosis (Cho and Nuttall 2001; Morello et al 2002; Gennari et al 2007) and in the US for breast cancer risk reduction (Vogel et al 2006; Gennari et al 2008). All three also have beneficial effects on serum lipids, but are associated with venous thromboembolism and hot flushes. Moreover, although tamoxifen has a positive effect on bone as well, the increased risk of endometrial cancer eliminates it as a possible therapy for postmenopausal osteoporosis. The effects of raloxifene on bone are well established. Clinical trials demonstrated that at a daily dose of $60 \mathrm{mg}$ is effective in the prevention and treatment of postmenopausal osteoporosis (Delmas et al 1997; Lufkin et al 1998; Ettinger et al 1999). This compound also lacks estrogenic activity at the uterus but is associated with adverse effects such as blood clots and vasomotor symptoms, including hot flushes. In addition, both preclinical and clinical reports suggested that both tamoxifen and raloxifene are considerably less potent than estrogen (Prestwood et al 2000; Weinstein et al 2003), in part due to their reduced bioavailability. Moreover, even though raloxifene treatment was able to prevent bone loss and the occurrence of vertebral fractures, its effect in the prevention of hip fractures is still uncertain. Actually, the benefits of these SERMs in reducing the risks of invasive breast cancer and vertebral fracture should be weighed against the increased risks of venous thromboembolism, fatal stroke, and in case of tamoxifen, uterine cancer. Moreover, up to $50 \%$ of women taking available SERMs for different indications reported moderate or severe vasomotor or gynecologic symptoms (especially vaginal dryness and hot flushes) that could hinder compliance. It is evident that there is a need for a SERM that has the desiderable tissue specific estrogenic and antiestrogenic actions with minimal side effects.

Bazedoxifene is potent new generation SERM, being developed to be used alone for the prevention and treatment of osteoporosis in postmenopausal women and in combination with conjugated equine estrogens for menopausal symptoms and prevention of postmenopausal osteoporosis (Gruber and Gruber 2004; Gennari et al 2007; Lewiecki 2007; Stump et al 2007). In this article the available published data about mechanism of action, dosing, pharmacokinetics and toxicity of this new SERM are reviewed.

\section{Chemistry, metabolism and pharmacokinetic profile}

Bazedoxifene acetate (WAY-140424, TSE-424) is an indole-based ER ligand with unique structural characteristics with respect to raloxifene and tamoxifen (Figure 1), and stringently selected to ensure an improved profile versus its predecessors (Komm and Lyttle 2001; Miller et al 2001; Komm et al 2005). The molecule was assembled by using raloxifene as a template and substituting an indole ring for the benzothioprine core (Gruber and Gruber 2004). The side chain of bazedoxifene is synthesized by alkylation of a 4-hydroxy benzyl alcohol with ethyl bromoacetate, followed by conversion of the alcohol to benzyl chloride with $\mathrm{SOCl}_{2}$ in tetrahydrofuran. Alkylation is achieved with $\mathrm{NaH}$ in dimethyl formamide, which yields an ester that is subsequently reduced with lithium aluminum hydride. The primary alcohol is converted to a bromide with carbon tetrabromide and triphenylphosphine. The bromide is then substituted with hexamethylenimine and the product is hydrogenated and converted to the acetate salt (1-[4-(2-azepan-1-yl-ethoxy)benzyl]-2-(4-hydr- oxy-phenyl)-3-methyl-1H-indol-5-ol acetic acid, bazedoxifene).

Bazedoxifene exerts significant estrogenic and antiestrogenic activity, both in vitro and in vivo, targeting any tissues that possess ERs, such as bone, uterus, breast, blood vessels, and liver. This SERM binds to both ER $\alpha$ and ER $\beta$, with a slight higher affinity for $\mathrm{ER} \alpha$. However, it is less $\mathrm{ER} \alpha$ selective than raloxifene, with an affinity for ER $\alpha$ (IC50 of $26 \mathrm{nM}$ ) that is about 10 -fold lower than $17 \beta$-estradiol (Miller et al 2001; Komm et al 2005). The dissociation constant for bazedoxifene is about $0.1 \mathrm{nM}$ for $\mathrm{ER} \alpha$ and $0.3 \mathrm{nM}$ for $\mathrm{ER} \beta$ (Stump et al 2007). 


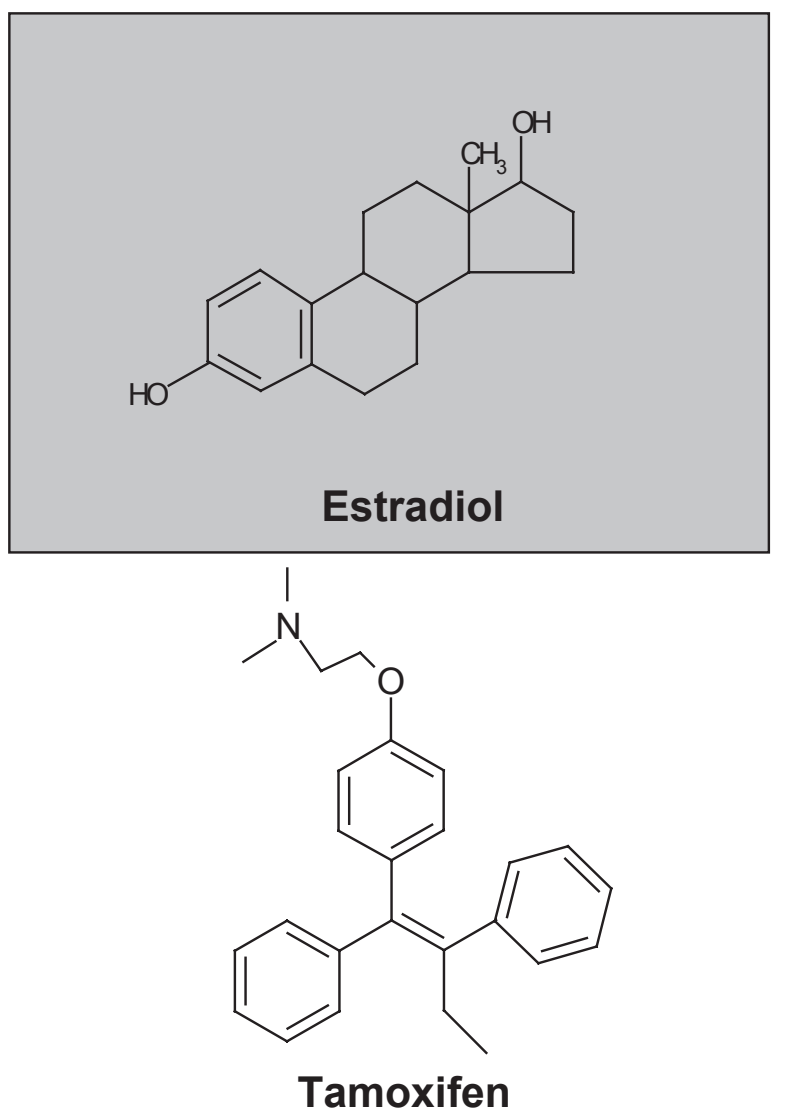<smiles>Cc1c(-c2ccc(O)cc2)n(Cc2ccc(OCCN3CCCCC3)cc2)c2ccc(O)cc12</smiles>

Bazedoxifene

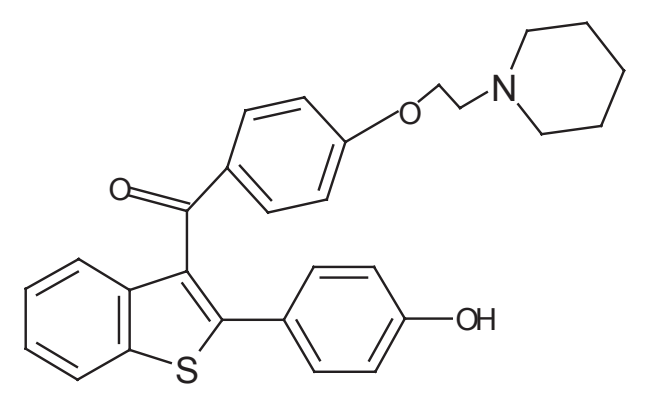

Raloxifene

Figure I Chemical structure of estradiol, bazedoxifene, and other currently approved SERMS.

The absolute and relative bioavailability of bazedoxifene was assessed in an open-label, randomized, three-way crossover study conducted in healthy postmenopausal women $(\mathrm{n}=18)$ under fasting conditions (Patat et al 2003). The two oral formulations (a 10-mg tablet and a 5-mg capsule) were bioequivalent with respect to AUC and the concentrationtime profiles. The absolute bioavailability of both formulations was approximately $6.2 \%$, which is 3 -fold the bioavailability of other SERMs. The metabolism of a single dose of $\left[{ }^{14} \mathrm{C}\right]$ bazedoxifene $(20 \mathrm{mg}$ ) was evaluated in a different study in 6 healthy, postmenopausal women (Chandrasekaran et al 2003). Blood, urine and feces were analyzed for radioactivity for 10 days. The major route of excretion was in the feces (84.7\%), with only a minor fraction $(0.81 \%)$ excreted in the urine. The major metabolic pathway was glucuronidation, with 40\%-95\% of metabolites being bazedoxifene-5-glucuronide. Moreover, there was little or no cytochrome P450 metabolism. To evaluate the pharmacokinetic and pharmacodynamic profile of bazedoxifene, a preliminary study with different oral doses $(1,2.5,5,10,20,40$, and $80 \mathrm{mg})$ was conducted for 30 days in 12 healthy postmenopausal women per cohort (Ermer et al
2000). Plasma concentrations increased in a linear fashion with a steady-state obtained by day 14 . From the study it was also anticipated that a $500 \mathrm{pg} / \mathrm{ml}$ plasma concentration may be necessary to produce a therapeutic effect. This concentration was achieved by both 5 and $10 \mathrm{mg}$ daily regimens, suggesting that these will provide efficacious effects in phase 2 and phase 3 studies. In a subsequent randomized, crossover, dose proportionality study different oral doses of bazedoxifene $(5,20$, or $40 \mathrm{mg})$ were given over 14 days in 23 postmenopausal women with a range of body weights from 53 to $79 \mathrm{~kg}$ (Ermer et al 2003). The drug showed a linear pharmacokinetics in the dose range tested, with maximum plasma concentration $\left(\mathrm{C}_{\max }\right)$ achieved 1-2 hours after dosing and a serum half-life $\left(\mathrm{t}_{1 / 2}\right)$ of about 28 hours. Protein binding was greater than $99 \%$, and the steady-state plasma concentration was achieved by day 7 , without unexpected drug accumulation.

Since bazedoxifene is metabolized by glucuronidation (as many other compounds), an open-label, randomized, 3-way crossover study in 12 healthy postmenopausal women was conducted to evaluate for possible drug-drug interactions between bazedoxifene and ibuprofen, a commonly used 
non-prescription nonsteroidal anti-inflammatory drug (Baird et al 2002). No significant interaction was observed, indicating that both drugs may be safely administered together without the need of dosage adjustment.

\section{Preclinical studies}

The preclinical data supporting bazedoxifene as an antiresorptive therapy for the prevention and treatment of postmenopausal osteoporosis are well documented. Several in vitro and in vivo experimental observations demonstrated that bazedoxifene interacts with both ERs inducing receptor transactivation and positively affecting the skeleton and the lipid profile without stimulating the endometrium and the breast or negatively impacting the central nervous system.

\section{Preclinical efficacy of bazedoxifene on bone}

In different studies in OVX rat model, bazedoxifene was effective in maintaining bone mass at a dose as low as $0.1 \mathrm{mg} / \mathrm{kg} /$ day, reaching maximal significant efficacy at a dose of $0.3 \mathrm{mg} / \mathrm{kg} /$ day (Komm and Lyttle 2001; Miller et al 2001; Komm et al 2005). Moreover, this dose maintained vertebral compressive strength (a surrogate for a reduced incidence of fracture) equivalent or better than the sham operated animals (Komm et al 2005). The histological quality of bone (assessed at the proximal tibia) was maintained and correlated well with the increases in BMD and compressive force data. In particular, bazedoxifene treatment prevented the loss in trabecular bone, and the increase in osteoclast number induced by ovariectomy, without affecting dynamic parameters of bone formation compared with sham operated animals (Komm et al 2005). Efficacy on most skeletal parameters appeared to be similar to other SERMs such as raloxifene and lasofoxifene (Black et al 1994; Ke et al 1998; Gennari et al 2007). Interestingly, in a more recent study in OVX monkeys, bazedoxifene treatment at dose levels up to $25 \mathrm{mg} / \mathrm{kg} /$ day for 18 months resulted in the partial preservation of bone mass (as determined by bone densitometry) and strength and in a significant prevention of OVX-induced increases in bone turnover (evaluated by biochemical markers and histomorphometric indices in cancellous and cortical bone) (Smith et al 2005).

A different study in OVX mice evaluated the ability of lasofoxifene $0.1 \mathrm{mg} / \mathrm{kg} /$ day, bazedoxifene $0.3 \mathrm{mg} / \mathrm{kg} /$ day and raloxifene $3 \mathrm{mg} / \mathrm{kg} /$ day or risedronate $1 \mathrm{mg} / \mathrm{kg}$ /day to enhance reversal of established osteopenia when co-administered with human PTH (hPTH) $10 \mathrm{mcg} / \mathrm{kg} /$ day s.c. After 4 weeks of treatment, total and trabecular BMD were 3\%-10\% higher in all of the cotreatment groups compared with the hPTH monotherapy group (Kharode et al 2003).

\section{Preclinical safety of bazedoxifene}

In all preclinical in vivo studies, bazedoxifene was well tolerated and was not associated with any adverse effects on plasma lipids or reproductive tract histology. Moreover, similar to raloxifene, bazedoxifene dose-dependently inhibited estrogen-induced MCF-7 breast cancer cell proliferation (Komm et al 2005). These data do not address the influence of this compound on normal mammary gland, but preliminary data in a rat mammary gland differentiation model showed that bazedoxifene does not act as estrogen, resulting in no detectable histological response (Komm et al 2003a). Importantly, an improved preclinical uterine profile of bazedoxifene over raloxifene was demonstrated. In fact, in the OVX mice model, bazedoxifene did not induce any change in uterine wet weight compared with OVX vehicle-treated animals, while raloxifene treatment significantly affected uterine wet weight. This difference was confirmed in a different and more sensitive preclinical model, the 3-day immature rat uterine model (Komm et al 2005). In these mice bazedoxifene produced a $35 \%$ increase in uterine wet weight at $0.5 \mathrm{mg} / \mathrm{kg}$ dose, but did not induce any change at a higher $(5.0 \mathrm{mg} / \mathrm{kg})$ dose. In contrast, raloxifene at equivalent treatment dosages significantly increased uterine weight by $75.9 \%-85.2 \%$. Histological examination of the entire uterus showed that bazedoxifene does not affect luminal epithelial cell hypertrophy or hyperplasia, myometrial hypertrophy, or luminal distention. Moreover, in the same model, cotreatment of bazedoxifene with raloxifene completely abrogated raloxifene-induced increase in myometrial or luminal epithelial cell hypertrophy, further supporting an improved uterine profile of bazedoxifene.

Potential effects of bazedoxifene on vasomotor reactivity and thermoregulation were also evaluated in a preclinical study using morphine-addicted rat model. This model represents an experimental paradigm designed to evaluate thermoregulatory response initiated by a naloxone injection to morphine-addicted animals (Katovitch et al 1986). Naloxoneinduced increase in tail skin temperature is ablated in rats pretreated with estradiol. In this animal model bazedoxifene alone, like raloxifene, did not act as estrogen agonist and did not blunt the thermoregulatory response to naloxone (Komm et al 2005). However, in contrast to raloxifene, no antagonism was observed when bazedoxifene was co-administered with 
$17 \beta$-estradiol at bone sparing efficacious doses $(0.3 \mathrm{mg} / \mathrm{kg})$. This suggested a potential lack of vasomotor effect of bazedoxifene in postmenopausal women. A different study indicated that bazedoxifene seems to maintain or increase nitric oxide synthase activity, implying a possible positive regulation of atherogenic processes, including monocyte adhesion, platelet aggregation, vascular smooth muscle cell proliferation and vasoconstriction (Wassmann et al 2002). Concerning this aspect, an increased effect on endothelial nitric oxide synthase activity has been reported in comparison with raloxifene.

Importantly, preclinical combination studies in OVX mice have been conducted to evaluate the effect of bazedoxifene when administered alongside conjugated estrogens (Premarin) or hPTH. At doses 7- to 10-fold higher than the bone efficacious dose, bazedoxifene antagonized the uterine stimulation of Premarin, without differences to untreated OVX controls. In contrast, positive skeletal effects were maintained, since OVX mice co-dosed with bazedoxifene $3 \mathrm{mg} / \mathrm{kg} /$ day and Premarin $2.5 \mathrm{mg} / \mathrm{kg} /$ day demonstrated BMD and cancellous bone compartments that were similar to sham-operated animals (Komm et al 2003a). A similar study compared the effects of the addition of different SERMs (raloxifene, bazedoxifene, and lasofoxifene) to the bone efficacious dose of conjugated estrogens. Even though no differences in skeletal parameters were noted for the 3 groups, only bazedoxifene was able to antagonize the effect of conjugated estrogen on uterine wet weight (Komm et al 2003b).

\section{Summary of preclinical evaluation of bazedoxifene}

Overall, preclinical data indicated that bazedoxifene (given either alone or in combination with conjugate estrogen) may represent a promising new treatment for osteoporosis, with a potential for less uterine and vasomotor effects than SERMs currently used in clinical practice. Like the other SERMs, in the tested OVX models the skeletal response in term of BMD gain appears lower than $17 \beta$-estradiol or bisphosphonates, but probably sufficient to result in a significant increase in bone strength.

\section{Clinical studies}

Notwithstanding the encouraging preclinical evidences, clinical available data on bazedoxifene treatment are limited. Several phase I trials have been conducted in healthy postmenopausal women to study the metabolism and pharmacokinetics of the compound, with no significant adverse effects (Morii 2000; Ermer et al 2000; Chandrasekaran et al 2003; Ermer et al 2003; Patat et al 2003; Gruber and Gruber 2004). Consistent with preclinical observations, in a preliminary 30-day study in healthy postmenopausal women, a significant $21 \%$ decrease in a marker of bone resorption (collagen C-link N-telopeptide) was observed (Ermer et al 2000). At daily doses ranging from 1 to $80 \mathrm{mg}$, a decrease in fibrinogen levels and no increase in vasomotor symptoms were also reported.

\section{Phase II studies of bazedoxifene acetate}

The preliminary efficacy and safety of 6 different doses of bazedoxifene in healthy postmenopausal women with increased bone turnover (defined as urinary N-terminal cross-linked telopeptides of type I collagen $>30 \mathrm{nmol} / \mathrm{mmol}$ creatinine) was tested in a phase II, 6-month, single-center, double-blind, randomized, active- and placebo-controlled study (Ronkin et al 2001; Ronkin et al 2005; Boudes et al 2003). This study was conducted in two parts. Part I studied 4 daily doses of bazedoxifene $(2.5 \mathrm{mg}, 5 \mathrm{mg}, 10 \mathrm{mg}$, and $20 \mathrm{mg}$ ), with respect to placebo or conjugated estrogens plus medroxyprogesterone acetate $0.625 / 2.5 \mathrm{mg}$. Because of favorable results, the trial was extended to study additional doses for part II, which subsequently enrolled women not previously randomized in part I, to 3 daily doses of bazedoxifene (20 mg, $30 \mathrm{mg}$, and $40 \mathrm{mg}$ ) or placebo. A total of 360 women were enrolled in Part I and 240 in Part II. All women also received supplemental calcium carbonate $600 \mathrm{mg} /$ day. In part I of the study, bazedoxifene at 2.5 to $20 \mathrm{mg} /$ day resulted in mean changes from baseline in self reported breast density and endometrial thickness that were not significantly different from placebo group. As expected, treatment with conjugated estrogens/medroxyprogesterone acetate resulted in a small but significant increase in endometrial thickness and breast pain compared with placebo (Ronkin et al 2001; Ronkin et al 2005). These positive results of bazedoxifene were confirmed in part II of the study. Interestingly, a statistically significant decrease in endometrial thickness relative to placebo was observed for both the 30- and 40-mg bazedoxifene dose. Regression analysis showed that bazedoxifene doses were inversely related to the change from baseline in endometrial thickness, suggesting greater endometrial antagonism as the dose of bazedoxifene increased. Moreover, the $40 \mathrm{mg}$ dose was also associated with a significant decrease in breast pain compared with placebo (Boudes et al 2003). At the skeleton, bazedoxifene produced a dose-dependent reduction of bone turnover markers compared with placebo at doses as low as 
$5 \mathrm{mg} /$ day (Ronkin et al 2001). When administered at doses of 20 or $40 \mathrm{mg}$, bazedoxifene reduced bone turnover by 20 and $26 \%$, respectively.

A different randomized, double-blind phase II study of bazedoxifene versus placebo for the evaluation of BMD in 375 Japanese patients with postmenopausal osteoporosis has been recently completed. No data have been released from this study.

\section{Phase III studies of bazedoxifene acetate}

phase III trials of bazedoxifene for postmenopausal osteoporosis had begun by October 2001 (Table 1), with over 10.000 women included worldwide. A first 2-year, multicenter, double-blind, randomized trial compared the efficacy of 3 bazedoxifene doses (10, 20, or $40 \mathrm{mg}$ ) with placebo and raloxifene $(60 \mathrm{mg})$ in 1434 postmenopausal women with osteopenia (BMD T score at the lumbar spine or femoral neck between -1.0 or -2.5 ) or clinical risk factors for osteoporosis (Miller et al 2007; Miller et al 2008). The primary endpoint was the percent BMD change at the lumbar spine at 24 months compared to placebo. Secondary endpoints included BMD change at the hip (total hip, femoral neck, and trochanter BMD at 6, 12, 18, and 24 months), bone turnover marker change (serum osteocalcin and type 1 collagen C-telopeptide at 3, 6, 9, 12, 18, and 24 months), and lipid changes at 3, 6, 12, 18, and 24 months. All doses of bazedoxifene and raloxifene prevented bone loss compared with placebo after 24 months of treatment. Mean differences in percent lumbar BMD change at 24 months relative to placebo were $1.08 \%, 1.41 \%, 1.49 \%$, and $1.49 \%$ for bazedoxifene
10,20 , and $40 \mathrm{mg}$ and raloxifene $60 \mathrm{mg}$, respectively. The differences in response between the bazedoxifene doses and between bazedoxifene and raloxifene were not statistically significant. However, only women receiving bazedoxifene $40 \mathrm{mg}$ experienced a significant increase from baseline in lumbar BMD at 6 and 12 months. Comparable BMD responses were observed with bazedoxifene and raloxifene at the femoral sites. Moreover, significant decreases in serum osteocalcin and type 1 collagen C-telopeptide levels from baseline and relative to placebo were observed with all active treatments as early as 3 months and were sustained throughout the study. A decrease in total and LDL cholesterol was also observed with bazedoxifene and raloxifene compared with placebo.

A different phase III, multicenter, double-blind, randomized, placebo-controlled study was specifically designed to evaluate the efficacy of bazedoxifene for the prevention of fractures (Silverman et al 2008). The study enrolled 7492 healthy postmenopausal women with osteoporosis with or without prevalent vertebral fractures. Participants were randomized to receive bazedoxifene (20 or $40 \mathrm{mg} /$ day), raloxifene $(60 \mathrm{mg})$, or placebo and calcium (1200 mg) plus vitamin D (400 IU) supplementation. The primary endpoint was the incidence of new vertebral fractures after 36 months. Secondary outcomes included breast cancer incidence, clinical vertebral fractures, worsening vertebral fractures, nonvertebral fractures, and height changes. Both bazedoxifene doses prevented the incidence of vertebral fractures relative to placebo, with a similar efficacy as raloxifene. The 3-year incidence of new vertebral fractures

Table I Clinical phase III trials of bazedoxifene in osteoporosis

\begin{tabular}{|c|c|c|c|c|}
\hline $\begin{array}{l}\text { Protocol ID } \\
\text { (date started) }\end{array}$ & Population (n) & Compound & Primary endpoints & Secondary endpoints \\
\hline $\begin{array}{l}\text { NCT0048I I69' } \\
\text { (July 200I) }\end{array}$ & $\begin{array}{l}\text { Caucasian } \\
\text { postmenopausal } \\
\text { women ( } n=1583 \text {; } \\
\text { BMD available for } \\
\text { I434) }\end{array}$ & $\begin{array}{l}\text { BAZ 10, } 20,40 \mathrm{mg} \text { vs } \\
\text { Raloxifene } 60 \mathrm{mg} \text { or } \\
\text { Placebo (+ calcium } \\
600 \mathrm{mg} \text { ) }\end{array}$ & Lumbar BMD change at 2 years & $\begin{array}{l}\text { Femoral BMD change at } 6,12,18, \\
24 \text { months; lipid profile and bone } \\
\text { markers }\end{array}$ \\
\hline $\begin{array}{l}\text { NCT002057772 } \\
\text { (October 200I) }\end{array}$ & $\begin{array}{l}\text { Caucasian } \\
\text { postmenopausal } \\
\text { women }(n=7492)\end{array}$ & $\begin{array}{l}\text { BAZ } 20,40 \mathrm{mg} \text { vs } \\
\text { Raloxifene } 60 \mathrm{mg} \text { or } \\
\text { placebo (+ calcium } \\
\text { I200 mg and vitamin D } \\
400 \mathrm{IU} \text { ) }\end{array}$ & $\begin{array}{l}\text { Incidence reduction of new } \\
\text { vertebral fractures at } 3 \text { years; } \\
\text { safety profile }\end{array}$ & $\begin{array}{l}\text { Breast cancer incidence; clinical } \\
\text { vertebral fractures; worsening } \\
\text { vertebral fractures; nonvertebral } \\
\text { fractures; height changes }\end{array}$ \\
\hline $\begin{array}{l}\text { NCT00384072 } \\
\text { (May 2006) }\end{array}$ & $\begin{array}{l}\text { Asian postmeno- } \\
\text { pausal women } \\
\text { (target } \mathrm{n}=500 \text { ) }\end{array}$ & BAZ $20 \mathrm{mg}$ vs placebo & $\begin{array}{l}\text { Lumbar BMD change after } \\
6 \text { months }\end{array}$ & $\begin{array}{l}\text { Femoral BMD change at } \\
6 \text { months; bone markers and lipid } \\
\text { profile at } 3 \text { and } 6 \text { months }\end{array}$ \\
\hline
\end{tabular}

'A multicenter, double-blind, randomized, placebo and raloxifene controlled study to assess the safety and efficacy of TSE-424 (bazedoxifene acetate) in the prevention of postmenopausal osteoporosis; ${ }^{2}$ Fracture incidence reduction and safety of TSE-424 (bazedoxifene acetate) compared to placebo and raloxifene in osteoporotic postmenopausal women; ${ }^{3} \mathrm{~A}$ multicenter, double-blind, randomized, placebo-controlled study to assess the safety and efficacy of bazedoxifene in postmenopausal Asian women. Abbreviation: BMD, bone mineral density. 
were $2.3 \%, 2.5 \%, 2.3 \%$, and $4.1 \%$ in the bazedoxifene $20 \mathrm{mg}$, bazedoxifene $40 \mathrm{mg}$, raloxifene $60 \mathrm{mg}$, and placebo groups, respectively, with a significant relative risk reduction for new vertebral fracture of $42 \%, 37 \%$, and $42 \%$, respectively, versus placebo (Figure $2 \mathrm{a}$ ). There was overall no treatment effect on non-vertebral fractures, with incidence rates of $5.7 \%$ and $5.6 \%$ for the bazedoxifene 20 - and $40-\mathrm{mg}$ treatment groups, respectively, compared with $5.9 \%$ for the raloxifene treatment group and 6.3\% for the placebo group (Figure 2a). However, in a post-hoc analysis of women with higher risk for fractures (low femoral neck T-score and multiple vertebral fractures, $\mathrm{n}=1,772$ ) bazedoxifene $20 \mathrm{mg}$ showed a $50 \%$ and $44 \%$ reduction in the risk of nonvertebral fracture compared with placebo $(\mathrm{HR}=0.50 ; 95 \% \mathrm{CI}, 0.28-0.90 ; \mathrm{p}=0.02$; $)$ or raloxifene $60 \mathrm{mg}(\mathrm{HR}=0.56 ; 95 \% \mathrm{CI}, 0.31-1.01 ; \mathrm{p}=0.05)$, respectively (Silverman et al 2008) (Figure 2b). A similar but not significant trend for reduced nonvertebral fracture incidence was also observed with bazedoxifene $40 \mathrm{mg}$.

Another multicenter, double-blind, randomized, phase III trial was designed to evaluate the percent change in lumbar spine BMD compared with baseline after 6 months of treatment with bazedoxifene $20 \mathrm{mg}$ /day or placebo in postmenopausal Asian women. Secondary efficacy outcomes were BMD at femoral sites, serum bone markers at 3 and 6 months or lipid profile. Participants were healthy Asian women who were $1-5$ years postmenopausal with at least 1 osteoporosis clinical risk factor, or at least 5 years postmenopausal with a T-score at the lumbar spine between -1.0 and -2.5 and at least 1 osteoporosis clinical risk factor. The study was completed in September 2007, but no data have been released [http://www.clinicaltrials.gov/ct/action/GetStudy].

\section{Clinical studies of bazedoxifene acetate} in combination with estrogen

Following the positive preclinical observation in the OVX mice model (Komm et al 2003a) and given its unique antiestrogenic action on the endometrium, specific trials have been designed to evaluate efficacy and safety profile of bazedoxifene combined with conjugate estrogen (bazedoxifene/CE). The rationale for selecting bazedoxifene as the SERM in this combination is that it may offset estrogen stimulation of endometrial and breast tissue, without the necessity of using a progestin in women with an intact uterus or aggravating menopausal vasomotor symptoms, while stabilizing or increasing BMD (Gruber and Gruber 2004; Lewiecki 2007; Stump et al 2007). This combination of a SERM with conjugated estrogen has lead to a new class of menopausal therapy called "tissue selective estrogen complex (TSEC)" (Bergmann Koury 2007; Komm et al 2007; Stovall and Pinkerton 2008).

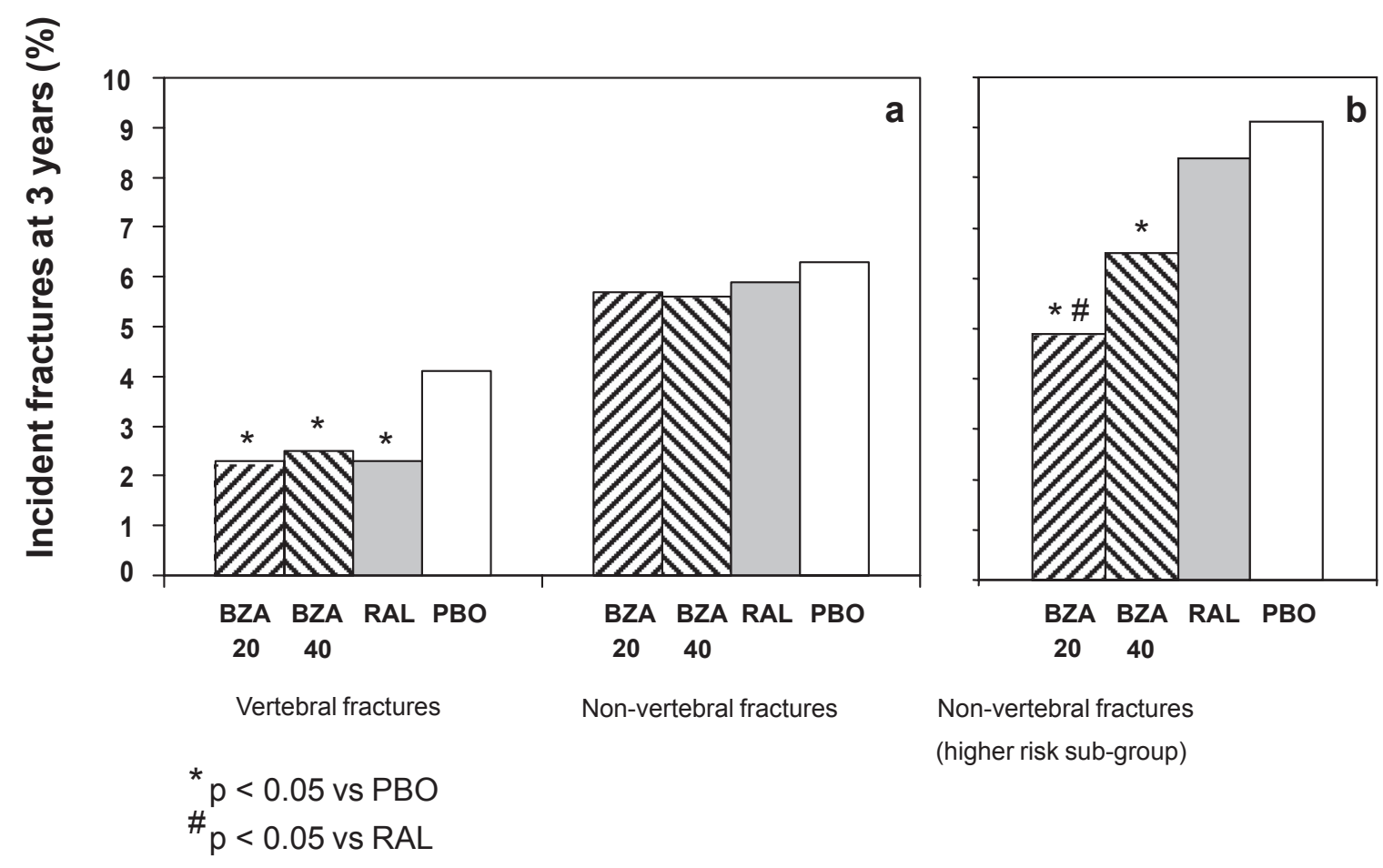

Figure 2 Percentage of incident fractures after 3 years of bazedoxifene acetate (BZA, 20 and $40 \mathrm{mg}$ ) treatment compared with raloxifene $60 \mathrm{mg}(\mathrm{RAL})$ and placebo (PB) in postmenopausal women (a) and in postmenopausal women at higher risk of fracture (b). Derived from data of the NCT00205777 trial (Silverman et al 2008). 
In phase II clinical trials several dose combinations of bazedoxifene/CE were tested with respect to bazedoxifene alone, conjugated estrogen or placebo in healthy postmenopausal women (Lewiecki 2007). A multicenter, randomized, double-blind, controlled pilot study explored the safety and efficacy of 6 doses of bazedoxifene/CE (bazedoxifene 5,10 , or $20 \mathrm{mg}$ combined with CE 0.3 or $0.625 \mathrm{mg}$ ) with respect to placebo, CE (0.3 and $0.625 \mathrm{mg}), \mathrm{CE} 0.625 \mathrm{mg}$ with medroxyprogesterone acetate $2.5 \mathrm{mg}$, and bazedoxifene $5 \mathrm{mg}$ alone (Van Duren et al 2006). The primary outcome was endometrial thickness as measured by transvaginal ultrasound at the end of the study (day 84). Other endpoints included hot flushes and the incidence of amenorrhea. Participants were 408 healthy postmenopausal women, with endometrial thickness less than $5 \mathrm{~mm}$, and an average of at least 4 hot flushes per day. As expected $\mathrm{CE}$ alone increased endometrial thickness. However, the addition of bazedoxifene to $\mathrm{CE}$ resulted in a dose-related decrease in endometrial thickness. At day 84, a statistically significant lower increase in endometrial thickness was observed in the bazedoxifene $20 \mathrm{mg} / \mathrm{CE} 0.3 \mathrm{mg}$, bazedoxifene $10 \mathrm{mg} / \mathrm{CE} 0.625 \mathrm{mg}$, and in the bazedoxifene $20 \mathrm{mg} / \mathrm{CE} 0.625 \mathrm{mg}$ groups as compared to the respective $\mathrm{CE}$-alone groups. Moreover, the changes in endometrial thickness for both $20 \mathrm{mg}$ bazedoxifene/CE combinations were not statistically different from placebo. All doses of bazedoxifene combined with CE $0.625 \mathrm{mg}$, and bazedoxifene $5 \mathrm{mg} / \mathrm{CE} 0.3 \mathrm{mg}$, had a significant reduction in frequency of hot flushes compared with all control groups. Amenorrhea was maintained for the duration of the study in $92 \%$ of placebo-treated subjects, and in $84.2 \%$ to $94.6 \%$ of subjects treated with bazedoxifene/CE formulations. Overall, these findings warranted further investigation in different trials.

Preliminary results from multicenter randomized, double-blind, placebo- and active-controlled phase III trial of bazedoxifene/CE for the prevention of endometrial hyperplasia and osteoporosis in postmenopausal women have been recently presented as abstracts in different meetings (Table 2). The selective estrogen menopause and response to therapy 1 (SMART-1) trial was a 2-year, double-blind, randomized, placebo-controlled phase III study with daily bazedoxifene 10,20 , or $40 \mathrm{mg}$ combined with CE ( 0.45 or $0.625 \mathrm{mg}$ ) compared with raloxifene $(60 \mathrm{mg})$ or placebo (Gallagher et al 2007; Lewis et al 2007). Participants were 3397 postmenopausal women, aged 45-70 years. Primary endpoint was the incidence of endometrial hyperplasia at 1 year; secondary endpoints included the incidence of endometrial hyperplasia at 2 years, breast pain and effects on BMD. Increasing doses of bazedoxifene/CE resulted in decreasing incidences of endometrial hyperplasia. In particular, the doses containing bazedoxifene 20 or $40 \mathrm{mg}$ paired with 0.45 or $0.625 \mathrm{mg}$ were associated with hyperplasia rates at 1 year below $1.0 \%$ that did not differ from placebo or raloxifene (Lewis et al 2007; Pickar et al 2007). Cumulative amenorrhea rates for all combinations containing bazedoxifene $20 \mathrm{mg}$ and $40 \mathrm{mg}$, and for bazedoxifene/CE $10 / 0.45 \mathrm{mg}$, were not significantly different than for placebo. Moreover, for all doses of bazedoxifene/CE the incidence

Table 2 Clinical phase III trials of bazedoxifene in combination with conjugated estrogen

\begin{tabular}{|c|c|c|c|c|c|}
\hline Protocol ID & Duration & Population & Compound & Primary endpoints & Secondary endpoints \\
\hline SMART-I & 2 years & $\begin{array}{l}\text { Postmenopausal } \\
\text { women }(n=3397)\end{array}$ & $\begin{array}{l}\text { BAZ I0, } 20,40 \mathrm{mg} \\
\text { combined with CE }(0.45 \\
\text { or } 0.625 \mathrm{mg}) \text { vs raloxifene } \\
60 \mathrm{mg} \text { or placebo }\end{array}$ & $\begin{array}{l}\text { Endometrial hyperplasia } \\
\text { (at I year) }\end{array}$ & $\begin{array}{l}\text { Endometrial hyperplasia } \\
\text { (at } 2 \text { years); breast pain; } \\
\text { effects on BMD }\end{array}$ \\
\hline SMART-2 & 12 weeks & $\begin{array}{l}\text { Postmenopausal } \\
\text { women with hot } \\
\text { flushes }(n=318)\end{array}$ & $\begin{array}{l}\text { BAZ } 20 \text { mg combined } \\
\text { with CE ( } 0.45 \text { or } \\
0.625 \mathrm{mg}) \text { vs placebo }\end{array}$ & $\begin{array}{l}\text { Moderate or severe hot } \\
\text { flushes at week } 4 \text { or } 12\end{array}$ & Breast pain; sleep quality \\
\hline SMART-3 & 12 weeks & $\begin{array}{l}\text { Postmenopausal } \\
\text { women with vaginal } \\
\text { atrophy }(n=652)\end{array}$ & $\begin{array}{l}\text { BAZ } 20 \text { mg combined } \\
\text { with CE ( } 0.45 \text { or } \\
0.625 \mathrm{mg}) \text { vs BAZ } 20 \mathrm{mg} \\
\text { or placebo }\end{array}$ & $\begin{array}{l}\text { Vaginal atrophy (superficial } \\
\text { and parabasal cells) }\end{array}$ & $\begin{array}{l}\text { Sexual function; menopause } \\
\text { related quality of life }\end{array}$ \\
\hline SMART-4 & 2 years & $\begin{array}{l}\text { Postmenopausal } \\
\text { women }(n=1083)\end{array}$ & $\begin{array}{l}\text { BAZ } 20 \text { mg combined } \\
\text { with CE }(0.45 \text { or } 0.625 \mathrm{mg}) \\
\text { vs CE }(0.45 \mathrm{mg}) / \\
\text { medroxyprogesterone } \\
\text { acetate (I.5 mg) or } \\
\text { Placebo }\end{array}$ & $\begin{array}{l}\text { Endometrial hyperplasia } \\
\text { (at I year); BMD change } \\
\text { at I year (osteoporosis } \\
\text { substudy) }\end{array}$ & $\begin{array}{l}\text { Uterine bleeding/spotting; } \\
\text { breast pain }\end{array}$ \\
\hline
\end{tabular}

Abbreviations: AE, adverse event; BMD, bone mineral density; BZA, bazedoxifene acetate; $C E$, conjugated estrogen; PB, placebo. 
of breast pain was similar to placebo (Bergmann Koury 2007; Lewiecki 2007). Taken together, these findings suggest that bazedoxifene/CE does not stimulate endometrial and breast tissue. The SMART-1 osteoporosis substudy enrolled 2315 postmenopausal women $(861 \leq 5$ years postmenopause and $1454>5$ years postmenopause) (Gallagher et al 2007; Lindsay et al 2007). After 2 years, all bazedoxifene/CE regimens were associated with greater increases in lumbar BMD (range, 1.15\%-2.61\%) compared with placebo $(-1.92 \%)$. Importantly, among women within 5 years postmenopause, the mean increase from baseline in lumbar spine BMD at 2 years was significantly greater with all bazedoxifene/CE doses (range, 1.15\%-2.61\%) compared with raloxifene $(0.15 \% ; \mathrm{p}<0.05)$ (Figure $3 \mathrm{a}$ and $\mathrm{b})$. Among women $>5$ years postmenopause, the increase from baseline in lumbar spine BMD at 2 years was significantly greater with TSECs containing bazedoxifene 10 and $20 \mathrm{mg}$ (range, $1.57 \%-2.42 \%)$ than with raloxifene $(0.73 \%$; $<<0.05)$. Similar results were observed for hip BMD. Moreover, greater suppression of bone turnover markers was observed with bazedoxifene/CE regimens compared with placebo (Bergmann Koury 2007). In two different selective estrogen menopause and response to therapy trials (SMART-2 and SMART-3) the efficacy of bazedoxifene/CE combination on vaginal dryness, hot flushes and other menopausal symptoms was investigated. In the 12-week SMART-2 study 318 postmenopausal women with 7 or more moderate to severe hot flushes per day or 50 or more per week were randomized to bazedoxifene/CE 20/0.45 and 20/0.65 mg or placebo (Pinkerton et al 2007). All treatment groups had fewer hot flushes from baseline at all time points. However,
bazedoxifene/CE groups had a significantly greater reduction in the number of moderate to severe hot flushes at weeks 4 and 12 compared with placebo, reaching a $74 \%$ to $80 \%$ decrease from baseline at week 12 (vs 51\% in placebo). There was also a statistical significant difference against placebo in the daily number of moderate to severe hot flushes in the bazedoxifene/CE 20/0.45 mg group from week 3 onward and in the bazedoxifene/CE 20/0.65 mg from week 2 onward. The incidence of breast pain did not differ from placebo. In addition, the bazedoxifene/CE-treated women had fewer sleep disturbances and improved sleep adequacy than placebo. The 12-week SMART-3 study was specifically designed to investigate the effects of bazedoxifene/CE on vaginal atrophy and sexual function in 652 postmenopausal women with moderate to severe vulvar/vaginal atrophy, vaginal $\mathrm{pH}>5.0$ or fewer superficial cells (Kagan et al 2007). Participants were randomized to four treatment groups: bazedoxifene/CE 20/0.45 $\mathrm{mg}$ and 20/0.625 $\mathrm{mg}$, bazedoxifene $20 \mathrm{mg}$ alone, or placebo. In the 601 women who completed the study, both the bazedoxifene/CE regimens showed increases in the percentage of superficial cells and decreases in parabasal cells compared with placebo. All active treatment groups resulted in a greater decrease in vaginal $\mathrm{pH}$ compared with placebo and a greater improvement in the most bothersome vulvar/vaginal atrophy symptom index. Moreover parameters of sexual function (Arizona Sexual Experiences Scale lubrication score and Menopause Specific Quality of Life total and sexual function scores) also improved in both bazedoxifene/CE doses compared with placebo. An additional phase III, 2-year study (SMART-4) compared the effects of bazedoxifene/CE (20/0.45 and 20/0.625 mg)
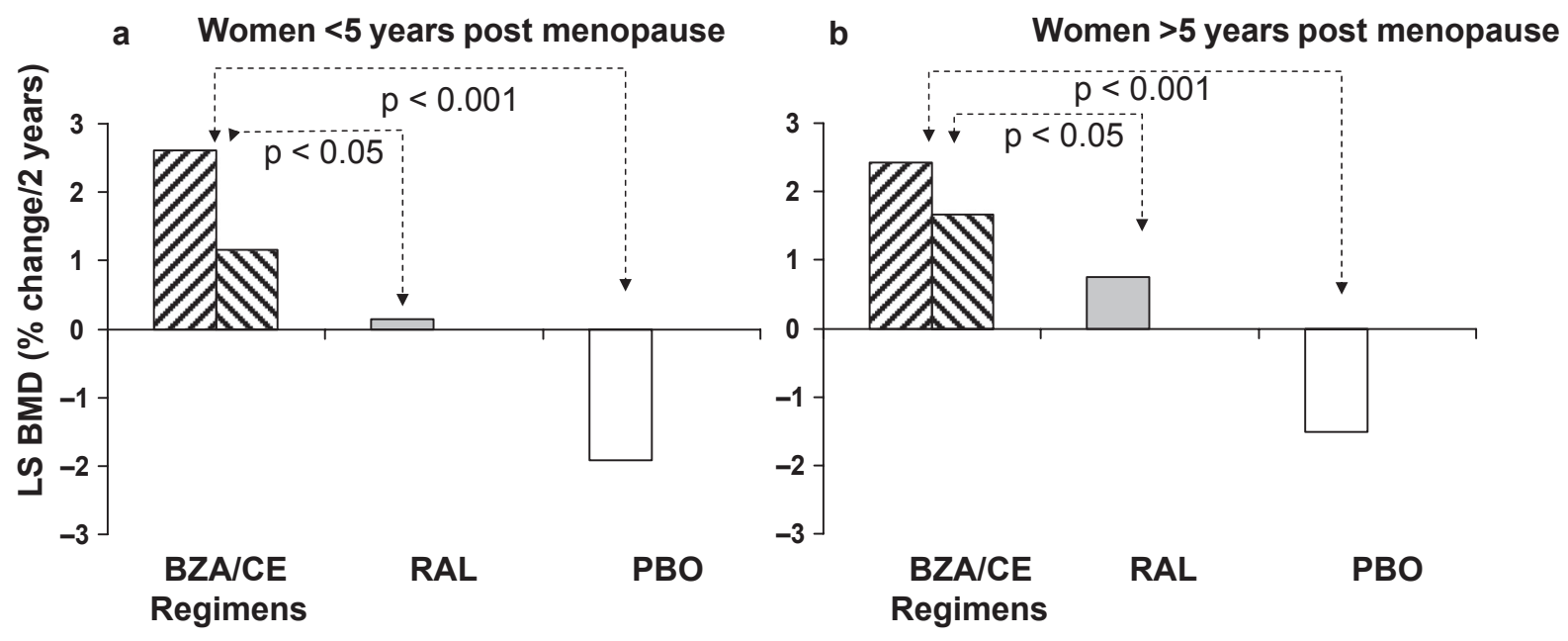

Figure 3 Comparison of the effects of bazedoxifene in combination with conjugated estrogen (at different regimens) on BMD with respect to raloxifene 60 mg and placebo in women within 5 years postmenopause (a) and after 5 years postmenopause (b). Derived from data of the SMART-I trial (Gallagher et al 2007; Lindsay et al 2007). 
to $\mathrm{CE} /$ medroxyprogesterone acetate $0.45 / 1.5 \mathrm{mg}$ or placebo in 1083 postmenopausal women. Primary endpoint was the rate of endometrial hyperplasia at 1 year. A SMART-4 trial osteoporosis substudy was also designed. No data are currently available from this trial.

\section{Side effects and contraindications}

In all clinical trials bazedoxifene, given either alone or in combination with $\mathrm{CE}$ appeared to be well tolerated, with few patients experiencing side effects.

phase I studies of bazedoxifene alone demonstrated that the compound is safe, with no toxicity at doses up to $80 \mathrm{mg}$, significantly higher than those currently used in ongoing phase II/III studies (Ermer et al 2000). In a phase II study with bazedoxifene acetate 20,30 , and $40 \mathrm{mg}$, the most commonly reported treatment-emergent adverse events were abdominal pain, headache, and flu syndrome (Ronkin et al 2005). Importantly, the $40 \mathrm{mg}$ bazedoxifene group experienced significantly less breast pain than placebo $(10.0 \%$ vs $25.4 \%)$. In phase II studies vasodilatation (hot flushes) was more common with bazedoxifene doses of 20 and $40 \mathrm{mg}$ (19.9\% and $22.6 \%$, respectively), than with placebo (13.2\%), but similar to raloxifene (18.3\%) (Chesnut et al 2007). Overall, two completed phase III studies confirmed the favorable safety profile of bazedoxifene given alone, even though with slightly different results (Table 3). The percentage of women who reported either worsening or the development of new hot flushes was higher in the bazedoxifene groups than in the placebo group in both studies, but similar to that observed in the raloxifene group. In contrast, the incidence of thrombotic events was low $(<1 \%)$ and similar to that with raloxifene or placebo in a phase III 2-year study (Chesnut et al 2007, Miller 2008), but slightly higher than placebo in a 3-year phase III study (Adachi et al 2007; Silverman et al 2008). The number of cases of breast cancer was low in these trials and did not differ from placebo or raloxifene. In all phase II and III studies, bazedoxifene at doses up to $40 \mathrm{mg}$ did not stimulate the endometrium, consistent with the preclinical data showing anti-uterotropic activity to inhibit estrogeninduced histological changes. Moreover, the addition of bazedoxifene to $\mathrm{CE}$ resulted in a dose-related decrease in endometrial thickness. Importantly, combinations of bazedoxifene/CE also showed a beneficial effect on vasomotor symptoms. In particular, bazedoxifene/CE at different doses significantly reduced the number and severity of hot flushes when compared with placebo (Van Duren et al 2006; Pinkerton et al 2007). The most commonly reported side effects of bazedoxifene/CE in a phase II trial (SMART-3) were headache and joint pain, even though their frequency

Table 3 Summary of safety profile in phase III trials of bazedoxifene

\begin{tabular}{|c|c|c|}
\hline Adverse event & Miller et al 2008 & Silverman et al 2008 \\
\hline Trial ID & NCT0048II69 & NCT00205777 \\
\hline Study length (months) & 24 & 36 \\
\hline Sample size $(n)$ & 1583 & 7492 \\
\hline Mean age $(y r s \pm S D)$ & $57.6 \pm 6.5$ & $66.4 \pm 6.7$ \\
\hline BZA treated subjects $(n)$ & 962 & 3758 \\
\hline BZA dose range (mg) & $10-40$ & $20-40$ \\
\hline Any AE (\% vs PB) & $94.4-95.3$ vs 95.8 & $95.7-96.8$ vs 96.2 \\
\hline Discontinuation due to $\mathrm{AE}$ (\% vs $\mathrm{PB}$ ) & $16.8-18.2$ vs 15.5 & |4.4-14.4 vs 12.7 \\
\hline Deaths (\% vs PB) & $0.0-0.9$ vs 0.3 & $0.7-0.9$ vs 0.6 \\
\hline Hot flushes (\% vs PB) & |9.6-24.I vs I4.2 ( $<<0.05)$ & $12.6-13.0$ vs $6.3(p<0.00 \mid)$ \\
\hline Leg cramps (\% vs PB) & $9.3-12.1$ vs 11.6 & 10.9 vs $8.2(p<0.01)$ \\
\hline Stroke (\% vs PB) & $0.0-0.3$ vs 0.3 & I.0 vs I.I \\
\hline Deep venous thrombosis (\% vs PB) & $0.0-0.6$ vs 0.3 & $0.4-0.5$ vs $0.1(p<0.05)$ \\
\hline Pulmonary embolous (\% vs PB) & $0.0-0.3$ vs 0.0 & $0.2-0.3$ vs 0.2 \\
\hline Breast cancer (\% vs PB) & $0.3-0.6$ vs 0.6 & $0.2-0.3$ vs 0.4 \\
\hline Fibrocystic breast disease (\% vs PB) & - & $0.6-0.7$ vs 1.0 \\
\hline Endometrial cancer (\% vs PB) & 0.0 vs 0.3 & $0.0-0.1$ vs 0.2 \\
\hline Endometrial hyperplasia (\% vs PB) & - & 0.1 vs 0.1 \\
\hline
\end{tabular}

Abbreviations: $A E$, adverse event; $B Z A$, bazedoxifene acetate; $P B$, placebo. 
was not significantly different from placebo. No specific contraindications have been described for the compound, given either alone or in combination with $\mathrm{CE}$.

\section{Conclusions and future directions}

Tissue selectivity is a fundamental component to the functional application of SERMs for the prevention and treatment of osteoporosis. Optimally, an ideal SERM would exhibit the positive attributes associated with HRT, which include skeletal protection, reduction of vasomotor symptoms and of vaginal atrophy, but also would not stimulate the uterus or the breast as seen with long term HRT. Additional benefits of the ideal compound would be a neutral or positive effect on cognition (particularly in regard to Alzheimer's disease) and a positive action on cardiovascular system. Even though currently available SERMs, tamoxifen and raloxifene have the potential to retain most of the beneficial effects of estrogen avoiding some of its adverse events, they are also responsible for side effects such as thromboembolic disorders, vasomotor symptoms and, concerning tamoxifen, uterine cancer. These contraindications represent a major concern especially for the type of long-term, chronic therapy that is required to prevent osteoporosis. Moreover, both preclinical and clinical reports suggest that these SERMs are considerably less potent than estrogen.

Bazedoxifene is a novel, stringently screened SERM that has been specifically designed as a preventive therapy for postmenopusal osteoporosis, without stimulating the uterus or the breast (Komm et al 2001). Like other SERMs, such as tamoxifen and raloxifene, bazedoxifene targets estrogen receptors leading to selective inhibition or stimulation of estrogen-like action in target tissues. Both preclinical and clinical data indicate that this SERM has a unique combination of attributes, making it an extremely attractive alternative for the treatment and prevention of osteoporosis.

In both preclinical and clinical studies this SERM showed a unique effect on the endometrium, with respect to the current available SERMs. Indeed, endometrial effects have been a focal point in the development of recent SERMs. Tamoxifen is known to cause endometrial proliferation and to increase endometrial cancer risk. The clinical development of different new SERMs such as idoxifene and levormeloxifene has been halted, partially due to their stimulatory effects on the uterus. In this context, bazedoxifene represents a clear improvement in this field (Ronkin et al 2005). In fact, no other SERM, including raloxifene, has been shown in preclinical and clinical studies to have antagonistic activity in the endometrium (Komm et al 2001; Ronkin et al 2005). Moreover, in phase III clinical trials of postmenopausal women this compound, at doses ranging from 20 to $60 \mathrm{mg} /$ day, demonstrated beneficial skeletal effects increasing BMD and preventing the occurrence of vertebral fractures compared to placebo, and with a similar efficacy than raloxifene. Indeed, treatment regimens with different compounds such bisphosphonates are known to produce a more pronounced increase in BMD when compared with all SERMs, including bazedoxifene (Liberman et al 1995; Hosking et al 1998; Ettinger et al 1999). However, the similar reductions in vertebral fracture rates seen with raloxifene, bazedoxifene and bisphosphonates in non head-to-head trials indicate that a greater increase in BMD does not necessarily correlate with a greater improvement of bone strength (Delmas and Seeman 2004; Seeman and Delmas 2006). Thus, different components of bone strength (ie, bone material properties and/or microarchitecture), not captured by changes in BMD, may contribute to the reduction in fracture risk observed with SERMs such as raloxifene and bazedoxifene. Moreover, a potentially increased effect on nonvertebral fracture prevention of bazedoxifene over placebo and raloxifene (at least in women at higher fracture risk) has been also shown (Silverman et al 2008), even though further studies are needed to confirm this issue. Overall, these data suggest that bazedoxifene may have a role in the treatment of postmenopausal osteoporosis. Based on promising results of phase III studies, bazedoxifene acetate is currently under FDA revision for the prevention and treatment of osteoporosis. An approvable FDA letter for prevention has already been released on April 2007, even though further analysis and discussion concerning the incidence of stroke and of venous thrombotic events have been advised. Indeed, the latter points constitute the major concerns about long term treatment with SERMs. Even though the overall incidence of venous thromboembolism in the active bazedoxifene treatment groups was very low in both phase III trials (below 1\%), it was significantly higher than placebo in one study (Silverman et al 2008). Further, long-term studies are needed to fully address this issue. In addition, fewer cases of breast cancer were reported in bazedoxifene treatment groups compared with the placebo and raloxifene groups, which may indicate a protective effect on breast cancer as has been shown with other SERMs. This issue also needs to be further investigated in breast cancer prevention trials, in order to fully understand the therapeutic potential of this new SERM.

Importantly, more recent clinical investigation has lead to the development of the first compound of a new class of menopausal therapy called TSEC, in which bazedoxifene has been combined with CE. Theoretically, this combination creates a compound with more balanced "estrogenic" response, that could potentially maximize drug benefits 
while minimizing adverse effects. This hypothesis seems to be confirmed by preliminary and yet unpublished data from phase III clinical trials that demonstrated a potentially improved skeletal profile of bazedoxifene/CE over raloxifene, in terms of BMD gain. Together with its favorable endometrial safety profile and improved efficacy for vasomotor symptoms the clinical profile of bazedoxifene/CE may change the way women and physicians approach menopausal symptoms. Thus, this treatment would particularly benefit postmenopausal women who suffer severe vasomotor symptoms and require bone protection. However, notwithstanding the encouraging and innovative preclinical and clinical evidences, available data from phase III trials are very limited and the efficacy of bazedoxifene/CE in the prevention of osteoporotic fractures remains unknown, as well as the optimal dosage for this combination. At the moment, insufficient clinical data and the lack of detailed information on long-term efficacy or possible side effects (ie, thromboembolic disorders) preclude a reasonable prediction of the future of this promising tissue selective estrogen complex.

\section{Disclosures}

The authors report no conflicts of interest.

\section{References}

Adachi JD, Chesnut CH, Brown JP, et al. 2007. Safety and Tolerability of Bazedoxifene in Postmenopausal Women with Osteoporosis: Results from a 3-Year, Randomized, Placebo- and Active-Controlled Clinical Trial. J Bone Miner Res, 22:S460.

Baird SJ, Mckeand WE, Ermer JC, et al. 2002. Lack of clinically relevant pharmacokinetic interaction between bazedoxifene and ibuprofen. Clin Pharmacol Ther, 71:P94.

Barrett-Connor E. 1995. The economic and human costs of osteoporotic fracture. Am J Med, 98:3S-8S.

Bergmann Koury C. 2007. TSECs may offer new option for menopausal symptom treatment, osteoporosis prevention. Review of Endocrinology, 45-6.

Black DM, Cummings SR, Genant HK, et al. 1992. Axial and appendicular bone density predict fractures in older women. $J$ Bone Miner Res, 7:633-8.

Black LJ, Sato M, Rowley ER, et al. 1994. Raloxifene (LY139481 HCI) prevents bone loss and reduces serum cholesterol without causing uterine hypertrophy in ovariectomized rats. J Clin Invest, 93:63-9.

Bord S, Horner A, Beavan S, et al. 2001. Estrogen receptors alpha and beta are differentially expressed in developing human bone. J Clin Endocrinol Metab, 86:2309-14.

Boudes P, Ronkin S, Korner S, et al. 2003. Effects of bazedoxifene (TSE424), a novel tissue selective estrogen receptor modulator (SERM), on the incidence of breast pain. Osteoporos Int, 14:S14.

Burge R, Dawson-Hughes B, Solomon DH, et al. 2007. Incidence and economic burden of osteoporosis-related fractures in the United States, 2005-2025. J Bone Miner Res, 22:465-75.

Center JR, Nguyen TV, Schneider D, et al. 1999. Mortality after all major types of osteoporotic fracture in men and women: an observational study. Lancet, 353:878-82.

Chandrasekaran A, Ermer J, McKeand W, et al. 2003. Bazedoxifene acetate metabolic disposition in healthy postmenopausal women. J Clin Pharmacol Ther, 73:47.
Chesnut CH, Christiansen C, Hoeck HC, et al. 2007. Safety and Tolerability of Bazedoxifene for the Prevention of Postmenopausal Osteoporosis. $J$ Bone Miner Res, 22:S460.

Cho CH, Nuttall ME. 2001. Therapeutic potential of oestrogen receptor ligands in development for osteoporosis. Emerging Drugs, 6:137-54.

Cooper C, Campion G, Melton III LJ. 1992. Hip fractures in the elderly: a world-wide projection. Osteoporos Int, 2:285-9.

Cummings SR, Black DM, Nevitt MC, et al. 1990. Appendicular bone density and age predict hip fracture in women: the study of Osteoporotic Fractures Research Group. JAMA, 263:665-8.

Cummings SR, Black DM, Nevitt MC, et al. 1993. Bone density at various sites for prediction of hip fractures. Lancet, 341:72-5.

Delmas PD, Bjarnason NH, Mitlak BH, et al. 1997. Effects of raloxifene on bone mineral density, serum cholesterol concentrations, and uterine endometrium in postmenopausal women. $N$ Engl J Med, 337:1641-7.

Delmas PD, Seeman E. 2004 Changes in bone mineral density explain little of the reduction in vertebral or nonvertebral fracture risk with anti-resorptive therapy. Bone, 34:599-604.

Ermer JC, Kotake A, Mckeand WE, et al. 2000. Clinical pharmacology of a novel tissue selective estrogen (WAY-140424) in postmenopausal women following administration for 30 days. J Bone Miner Res, 15:S436.

Ermer J, McKeand W, Sullivan P, et al. 2003. Bazedoxifene acetate dose proportionality in healthy postmenopausal women. J Clin Pharmacol Ther, 73:46.

Ettinger B, Black DM, Mitlak BH, et al. 1999. Reduction of vertebral fracture risk in postmenopausal women with osteoporosis treated with raloxifene: results from a 3-year randomized clinical trial. Multiple Outcomes of Raloxifene Evaluation (MORE) Investigators. [erratum in JAMA 1999 282:2124]. JAMA, 282:637-45.

Gallagher JC, Lindsay R, Dietrich J, et al. 2007. Smart trials: effects of a tissue selective estrogen complex (TSEC) comprised of bazedoxifene (BZA) and conjugated estrogens (CEs) on bone mineral density (BMD) in postmenopausal women. Fertil Steril, 88:S241.

Gennari L, Nuti R, Bilezikian JP. 2004. Aromatase activity and bone homeostasis in men. J Clin Endocrinol Metab, 89:5898-907.

Gennari L, Merlotti D, Valleggi F, et al. 2007. Selective estrogen receptor modulators for postmenopausal osteoporosis: current state of development. Drugs Aging, 24:361-79.

Gennari L, Merlotti D, De Paola V, et al. 2008. Raloxifene in breast cancer prevention. Expert Opin Drug Saf, 7:259-70.

Gruber C, Gruber D. 2004 Bazedoxifene (Wyeth). Curr Opin Investig Drugs, 5:1086-93.

Gustafsson JA. 1999. Estrogen receptor beta-a new dimension in estrogen mechanism of action. $J$ Endocrinol, 163:379-83.

Hosking D, Chilvers CE, Christiansen C, et al. 1998. Prevention of bone loss with alendronate in postmenopausal women under 60 years of age. Early Postmenopausal Intervention Cohort Study Group. $N$ Engl $J$ Med, 338:485-92.

Hui SL, Slemenda CW, Carey MA, et al. 1995. Choosing between predictors of fractures. J Bone Miner Res, 10:1816-22.

International Osteoporosis Foundation 1999. Survey by Helmut Minne, November 1999.

Kagan R, Gass M, Willilams RS, et al. 2007. SMART-3: Effects of the tissue selective oestrogen complex (TSEC) bazedoxifene (BZA) and conjugated oestrogens (CE) on vulvar/vaginal atrophy (VVA) and sexual function in postmenopausal women. Menopause, 14:1081.

Katovich MJ, Simpkins JW, Berglund LA, et al. 1986. Regional skin temperature changes in a rat model for the menopausal hot flush. Maturitas, 8:67-76.

Ke HZ, Paralkar VM, Grasser WA, et al. 1998. Effects of CP-336,156, a new, nonsteroidal estrogen agonist/antagonist, on bone, serum cholesterol, uterus and body composition in rat models. Endocrinology, 139:2068-76.

Kharode YP, Green PD, Marzolf JT, et al. 2003. Comparison of the effects of bazedoxifene, raloxifene, lasofoxifene and risedronate, co-treatment on h-PTH-induced reversal of established osteopenia in ovariectomized rats. J Bone Miner Res, 18:S273. 
Khosla S, Melton LJ III, Riggs BL. 2002. Clinical review 144: Estrogen and the male skeleton. J Clin Endocrinol Metab, 87:1443-50.

Komm BS, Lyttle CR. 2001. Developing a SERM: stringent preclinical selection criteria leading to an acceptable candidate (WAY-140424) for clinical evaluation. Ann NY Acad Sci, 949:317-26.

Komm BS, Kharode YP, Bodine PV, et al. 2003a. Bazedoxifene + conjugated estrogens: a balanced combination to provide optimal "estrogenic" safety and efficacy. J Bone Miner Res, 18:S272.

Komm BS, Kharode Y, Bodine P, et al. 2003b. Combining a SERM with conjugated estrogens (CE) to improve the SERM profile: not all SERMs may succeed. J Bone Miner Res, 18:S273.

Komm BS, Kharode YP, Bodine PV. 2005. Bazedoxifene acetate: a selective estrogen receptor modulator with improved selectivity. Endocrinology, 146:3999-4008.

Komm BS, Nagpal S, Chang KCN, et al. 2007. Tissue selective estrogen complexes (TSECs): optimal menopausal therapy. Presented at ENDO. June 4, 2007. Toronto.

Lewiecki EM. Bazedoxifene and bazedoxifene combined with conjugated estrogens for the management of postmenopausal osteoporosis. Expert Opin Investig Drugs, 2007 16:1663-72.

Lewis V, Pinkerton JV, Carr B, et al. 2007. Smart trials: endometrial effects of the tissue selective estrogen complex (TSEC) comprised of bazedoxifene (BZA)/conjugated estrogens (CEs). Fertility and Sterility, 88:S242.

Liberman UA, Weiss SR, Broll J, et al. 1995 Effect of oral alendronate on bone mineral density and the incidence of fractures in postmenopausal osteoporosis. The Alendronate Phase III Osteoporosis Treatment Study Group. N Engl J Med, 333:1437-43.

Lindsay R, Ronkin S, Constantine G, et al. 2007. A double-blind, placebo-controlled, phase 3 study of bazedoxifene/conjugated estrogens in postmenopausal women: Effects on BMD. Presented at ENDO, June 4, 2007. Toronto.

Lufkin EG, Whitaker MD, Nickelsen T, et al. 1998. Treatment of established postmenopausal osteoporosis with raloxifene: a randomized trial. J Bone Miner Res, 13:1747-54.

Manson JE, Hsia J, Johnson KC et al. 2003. Women's Health Initiative Investigators. Estrogen plus progestin and the risk of coronary heart disease. $N$ Engl J Med, 349:523-34.

Melton LJ, Thamer M, Ray NF, et al. 1997. Fractures attributable to osteoporosis: report from the national osteoporosis foundation. $J$ Bone Miner Res, 12:16-23.

Melton LJ, Atkinson EJ, Cooper C, et al. 1999. Vertebral fractures predict subsequent fracture. Osteoporos Int, 10:214-21.

Miller CP, Collini MD, Tran BD. 2001. Design, synthesis, and preclinical characterization of novel, highly selective indole estrogens. $J$ Med Chem, 44:1654-7.

Miller PD, Christiansen C, Hoeck HC, et al. 2007. Efficacy of Bazedoxifene for Prevention of Postmenopausal Osteoporosis: Results of a 2-Year, Phase III, Placebo- and Active-Controlled Study. J Bone Miner Res, 22:S59.

Miller PD, Chines A, Christiansen C, et al. 2008. Effects of Bazedoxifene on Bone Mineral Density and Turnover in Postmenopausal Women: 2-Year Results of a Randomized, Double-Blind, Placebo- and Active-Controlled Study. J Bone Miner Res, 23:525-35.

Morello KC, Wurz GT, DeGregorio MW. 2002. SERMs: current status and future trends. Crc Crit Rev Oncol Hematol, 43:63-76.

Osteoporosis Prevention, Diagnosis, and Therapy Consensus Statement 2000. JAMA, 2001, 285: 785-95.

Morii H. 2000. American Society for Bone and Mineral Research 22nd Annual Meeting (Part III), Osteoporosis Drugs, Toronto, Canada, 22-26 September 2000. IDDB Meeting Report, September 22-6.
Patat A, McKeand W, Baird Bellaire S, et al. 2003. Absolute/relative bioavailability of badezoxifene acetate in healthy postmenopausal women. Clin Pharmacol Ther, 73:43.

Pickar J, Archer DF, Constantine G, et al. 2007. A double-blind, placebo-controlled, phase 3 study of bazedoxifene/conjugated estrogens in postmenopausal women: Effects on endometrium. Presented at ENDO. June 4. Toronto.

Pinkerton JV, Utian WH, Constantine G et al. 2007. SMART-2: A phase III study of the efficacy and safety of bazedoxifene/conjugated estrogens for the treatment of menopausal vasomotor. Menopause, 14:1081.

Prestwood KM, Gunness M, Muchmore DB, et al. 2000. A comparison of the effects of raloxifene and estrogen on bone in postmenopausal women. J Clin Endocrinol Metab, 85:2197-202.

Riggs BL, Khosla S, Melton LJ III. 1998. A unitary model of involutional osteoporosis: estrogen deficiency causes both type I and type II osteoporosis in postmenopausal women and contributes to bone loss in aging men. $J$ Bone Miner Res, 13:763-73.

Riggs BL, Khosla S, Melton LJ III. 2002. Sex steroids and the construction and conservation of the adult skeleton. Endo Rev, 23:279-302.

Riggs BL, Hartmann LC. 2003. Selective Estrogen-Receptor ModulatorsMechanisms of Action and Application to Clinical Practice. N Engl J Med, 348:618-29.

Ronkin S, Clarke L, Boudes P, et al. 2001. TSE-424, a novel tissue selective estrogen, reduces biochemical indices of bone metabolism in a dose related fashion. $J$ Bone Miner Res, 16:S413.

Ronkin S, Northington R, Baracat E et al. 2005. Endometrial effects of bazedoxifene acetate, a novel selective estrogen receptor modulator, in postmenopausal women. Obstet Gynecol, 105:1397-1404.

Seeman E, Delmas PD. 2006. Bone quality-the material and structural basis of bone strength and fragility. N Engl J Med, 354:2250-61.

Silverman SL, Christiansen C, Genant HK, et al. 2008 Efficacy of bazedoxifene in reducing new vertebral fracture risk in postmenopausal women with osteoporosis: results from a 3-year, randomized, placebo- and active-controlled clinical trial. J Bone Miner Res, Jul 29. [Epub ahead of print].

Smith SY, Minck D, Jolette J, et al. 2005. Bazedoxifene prevents ovariectomy-induced bone loss in the Cynomolgus Monkey. J Bone Miner Res, 20:S174.

Stovall DW, Pinkerton JV. 2008. Estrogen agonists/antagonists in combination with estrogen for prevention and treatment of menopauseassociated signs and symptoms. Future Medicine, 4:257-68.

Stump AL, Kelley KW, Wensel TM. 2007. Bazedoxifene: a third-generation selective estrogen receptor modulator for treatment of postmenopausal osteoporosis. Ann Pharmacother, 41:833-9.

Van Duren D, Ronkin S, Pickar J, et al. 2006. Bazedoxifene combined with conjugated estrogens: a novel alternative to traditional hormone therapies. Fertil Steril, 86:S88-S89.

Vassilopoulou-Sellin R. 2003. Breast cancer and hormonal replacement therapy. Ann N Y Acad Sci, 997:341-50.

Vogel VG, Costantino JP, Wickerham DL, et al. 2006. Effects of tamoxifen vs raloxifene on the risk of developing invasive breast cancer and other disease outcomes: the NSABP Study of Tamoxifen and Raloxifene (STAR) P-2 trial. JAMA, 295:2727-41.

Wassmann S, Laufs U, Stamenkovic D, et al. 2002. Raloxifene improves endothelial dysfunction in hypertension by reduced oxidative stress and enhanced nitric oxide production. Circulation, 105:2083-91.

Weinstein RS, Parfitt AM, Marcus R, et al. 2003. Effects of raloxifene, hormone replacement therapy, and placebo on bone turnover in postmenopausal women. Osteoporos Int, 14:814-22. 